\title{
Malaria rapid diagnostic test transport and storage conditions in Burkina Faso, Senegal, Ethiopia and the Philippines
}

Audrey Albertini ${ }^{1 *}$, Evan Lee ${ }^{1}$, Sheick Oumar Coulibaly ${ }^{2}$, Markos Sleshi $^{3}$, Babacar Faye ${ }^{4}$, Mary Lorraine Mationg ${ }^{5}$, Kadi Ouedraogo ${ }^{2}$, Abeba G Tsadik ${ }^{3}$, Sendeaw Maksha Feleke³, Ibrahima Diallo ${ }^{6}$, Oumar Gaye ${ }^{4}$, Jennifer Luchavez ${ }^{5}$, Jessica Bennett ${ }^{1}$ and David Bell ${ }^{1}$

\begin{abstract}
Background: As more point of care diagnostics become available, the need to transport and store perishable medical commodities to remote locations increases. As with other diagnostics, malaria rapid diagnostic tests (RDTs) must be highly reliable at point of use, but exposure to adverse environmental conditions during distribution has the potential to degrade tests and accuracy. In remote locations, poor quality diagnostics and drugs may have significant negative health impact that is not readily detectable by routine monitoring. This study assessed temperature and humidity throughout supply chains used to transport and store health commodities, such as RDTs.

Methods: Monitoring devices capable of recording temperature and humidity were deployed to Burkina Faso (8), Senegal (10), Ethiopia (13) and the Philippines (6) over a 13-month period. The devices travelled through government supply chains, usually alongside RDTs, to health facilities where RDTs are stored, distributed and used. The recording period spanned just over a year, in order to avoid any biases related to seasonal temperature variations.

Results: In the four countries, storage and transport temperatures regularly exceeded $30.0^{\circ} \mathrm{C}$; maximum humidity level recorded was above $94 \%$ for the four countries. In three of the four countries, temperatures recorded at central storage facilities exceeded pharmaceutical storage standards for over $20 \%$ of the time, in another case for a majority of the time; and sometimes exceeded storage temperatures at peripheral sites.

Conclusions: Malaria RDTs were regularly exposed to temperatures above recommended limits for many commercially-available RDTs and other medical commodities such as drugs, but rarely exceeded the recommended storage limits for particular products in use in these countries. The results underline the need to select RDTs, and other commodities, according to expected field conditions, actively manage the environmental conditions in supply chains in tropical and sub-tropical climates. This would benefit from a re-visit of current global standards on stability of medical commodities based in tropical and sub-tropical climatic zones.
\end{abstract}

Keywords: Malaria, Rapid Diagnostic Tests, RDTs, Drugs, Storage, Transport, Temperature monitoring, Stability, Temperature, Humidity

\footnotetext{
* Correspondence: audrey.albertini@finddiagnostics.org

${ }^{1}$ Foundation for Innovative New Diagnostics (FIND), Geneva, Switzerland

Full list of author information is available at the end of the article
} 


\section{Background}

A major challenge for health systems in the tropics and sub-topics in the delivery of health care to remote and rural populations is maintaining the quality of commodities from time of entry to the country to time of use. Diagnostics and drugs can be subject to prolonged storage and transport where ambient temperature and humidity are high, while resources for environmental control are limited. The accelerated increase in the use of malaria rapid diagnostic tests (RDTs), perishable biological tests based on capture of parasite antigen by antibodies (protein) stabilized on a nitro-cellulose (organic) strip, has raised the profile of this issue within many health services in malaria-endemic regions. While emphasis on the manufacture of stable tests is essential in addressing this [1-4], understanding and managing the subsequent transport and storage of RDTs, and matching product stability to these conditions, is essential to ensure that misdiagnosis and subsequent avoidable mortality do not occur.

The WHO recommends parasitological confirmation of malaria by microscopy or alternatively by rapid diagnostic tests (RDTs) in all patients suspected of malaria before treatment initiation [5]. As most people at risk have poor access to reliable microscopy, widespread use of RDTs in remote, hard-to-supply areas is therefore essential to implement this policy [6]. Typically, RDTs and other health commodities arrive at a central warehouse, from where they may be distributed to regional or district facilities, or directly to peripheral health facilities. Recommendations on storage and transport recommend minimizing storage time at clinic level, but long peripheral storage may be necessary to maintain adequate safety stocks. A previous study in South East Asia reported storage beyond RDT manufacturer limits [7]. Such temperatures have been shown to degrade some commercially available tests [4].

Standards for registration of perishable medical commodities (drugs and in-vitro diagnostics) of the International Conference on Harmonization (ICH) and the Global Harmonization Task Force are well defined for cooler, temperate regions (Climatic Zones I and II) [8]. For climatic Zones III (hot/dry) and IV (hot/humid), $\mathrm{ICH}$ recommended a minimum stability for 1 year at $30^{\circ} \mathrm{C}$ and $35 \%$ humidity (Zone III) and $30^{\circ} \mathrm{C}$ and $65 \%$ humidity (Zone IV) [9]. While noting the ASEANrecommended variant of $30^{\circ} \mathrm{C}$ and $75 \%$ humidity for Zone IV [10], the WHO still endorses the former ICH guidelines for Zones III and IV for pharmaceuticals [11], which commonly share supply lines with diagnostics. The adequacy of these standards is crucial to malaria management, as the countries concerned are often limited in their ability to control storage conditions. Furthermore remoteness and limits in capacity for managing stocks often require total product life-spans of well over the 12 months on which ICH criteria are based.

This study aimed to gather data on actual temperatures and humidity levels, in different climatic zones, to which RDTs are subjected as they move through the supply chains that typically serve malaria-endemic countries to assess the appropriateness of RDTs procured in each country programme in terms of thermal stability. With the wide roll-out of RDTs in recent years and limited capacity for quality control once RDTs are dispersed from the central warehouse, understanding the likely environment in which RDTs are transported and stored is vital for procurement decisions and patient safety.

\section{Methods}

The study monitored temperature and humidity in storage facilities and health facilities in four malariaendemic countries: Senegal, Burkina Faso, Ethiopia, and the Philippines. All are in ICH Climatic Zones III and IV [8], but have a range of climatic conditions. Temperature data collection was carried out during storage and transport events occurring in selected sites in each country during the study period. These were compared with the manufacturer-recommended product storage temperatures of each product at the time of the study.

\section{Temperature and humidity recordings}

Temperatures and humidity were recorded using electronic monitors ( $\operatorname{LogTag}^{\circledR}$ HAXO-8 Humidity \& Temperature Recorder; ACR Systems, New Zealand, Range $-40^{\circ} \mathrm{C}$ to $+85^{\circ} \mathrm{C}\left[ \pm 0.5^{\circ} \mathrm{C}\right]$ and $0 \%$ to $100 \% \mathrm{RH}[ \pm$ $3 \mathrm{RH}])$. The monitors are equipped with a button which enables users to record a "mark" in the data stream, with a corresponding date and time, to be used when an event occurs, such as when transport left, or arrived at, a storage facility. The monitors were sent to the field inside envelopes with a form on the back allowing field collaborators to record relevant events. For the purposes of this study, LogTag monitors were either stored and transported alongside RDTs, or placed in locations where RDTs are routinely stored. The monitors were set to capture temperature and humidity data every two hours in storage facilities, while those specifically sent with transport were programmed to record every 30 or 60 minutes. Stored data was downloaded from the LogTag monitors and the mean temperatures were calculated using Microsoft Excel.

\section{Senegal \\ Climate}

Senegal, a coastal country extending into the arid Sahel, has a tropical climate with dry and rainy seasons. Average annual minimum and maximum temperatures range 
between $18^{\circ} \mathrm{C}$ and $30^{\circ} \mathrm{C}$ on the coast and $24^{\circ} \mathrm{C}$ and $40^{\circ} \mathrm{C}$ inland, with a maximum temperature of around 50 degrees (National Agency of Meteorology Senegal, unpublished data, 2010).

\section{Supply chain and storage facilities}

On delivery to the public sector, malaria RDTs are stored in the National Supply Pharmacy in Dakar, a non-air-conditioned site, prior to distribution. Temperature and humidity were monitored in the National Supply Pharmacy, two regional supply pharmacies, three district pharmacies, three health posts and one health hut (the lowest level of public-sector health care delivery). Transport data (by truck, car and bicycle) was collected from the central store to peripheral stores.

\section{Study timeline}

Data was collected over 13 months, from December 2009 to January 2011.

\section{Malaria RDT}

The test used in the National Malaria Control Programme (NMCP) during the study had a manufacturerrecommended storage temperature range from 1 to $40^{\circ} \mathrm{C}$, and was detecting HRP2 (Histine-rich protein 2) antigens (single test line).

\section{Burkina Faso \\ Climate}

Burkina Faso is a landlocked Sahel country with climatic zones ranging from very arid in the north to humid in the south, with distinct dry and rainy seasons. There is wide variation in temperatures, with an annual range between $5^{\circ} \mathrm{C}$ and $47^{\circ} \mathrm{C}$ (Institut Géographique du Burkina, unpublished data, 2011).

\section{Supply chain and storage facilities}

Temperatures and relative humidity were monitored in the central store (CAMEG - Centrale d'achat de Médicaments Essentiels Génériques) in Ouagadougou, one regional store where public-sector procurement is initially received, two health district stores, and three health center stores. Transport data (by van and truck) was collected from the central store to regional stores (3) and from regional stores to health district stores (3). RDTs were not kept under air-conditioning in any of these facilities.

\section{Study timeline}

Data was collected over a period of 12 months, from August 2009 to August 2010.

\section{Malaria RDT}

The RDT procured by the NMCP of Burkina Faso during the study had a recommended temperature storage range of $1^{\circ} \mathrm{C}$ to $40^{\circ} \mathrm{C}$; this product was targeting both pLDH (Plasmodium lactate deshydrogenase) and HRP2 antigens (two test lines).

\section{Ethiopia \\ Climate}

The mean annual temperatures in Ethiopia range from $10^{\circ} \mathrm{C}$ to $40^{\circ} \mathrm{C}$, the maximum occurring in the lowlands, while the climate is milder in the central highlands, much of which are malaria-free [12].

\section{Supply chain and storage facilities}

Temperature and humidity were monitored in the central store (PFSA - Pharmaceutical Fund and Supply Agency) in Addis Ababa where they were temporarily stocked before distribution to three regional stores, three health center stores and six health posts in the regions. None of these facilities had air-conditioning.

\section{Study timeline}

Data was collected over a period of 13 months, from December 2009 to January 2011.

\section{Malaria RDT}

The two malaria RDTs in use during this study had storage recommendations of $4{ }^{\circ} \mathrm{C}$ to $30^{\circ} \mathrm{C}$ and $4{ }^{\circ} \mathrm{C}$ to $45^{\circ} \mathrm{C}$, respectively. One product targeted both $\mathrm{pLDH}$ and HRP2 antigens (two test lines), while the other only HRP2 antigen (single test line).

\section{The Philippines}

\section{Climate}

The Philippines is an island country with a tropical climate and a mean annual temperature of $26.6^{\circ} \mathrm{C}$. During the hot season, temperatures rise above $36^{\circ} \mathrm{C}$ [13].

\section{Supply chains and storage facilities}

Temperature and humidity were monitored at the Department of Health Central Warehouse in Manila, in two regional warehouses and at health centers in three remote villages. None of these facilities was air-conditioned. Temperatures were also recorded during transport direct from the Central Warehouse to two villages.

\section{Study timeline}

Data was collected over a period of 15 months, from June 2009 to September 2010.

\section{Malaria RDT}

The malaria RDTs distributed during the study had recommended storage temperatures from $4^{\circ} \mathrm{C}$ to $45^{\circ} \mathrm{C}$, 
Table 1 Summary table of RDT storage temperatures and humidity levels

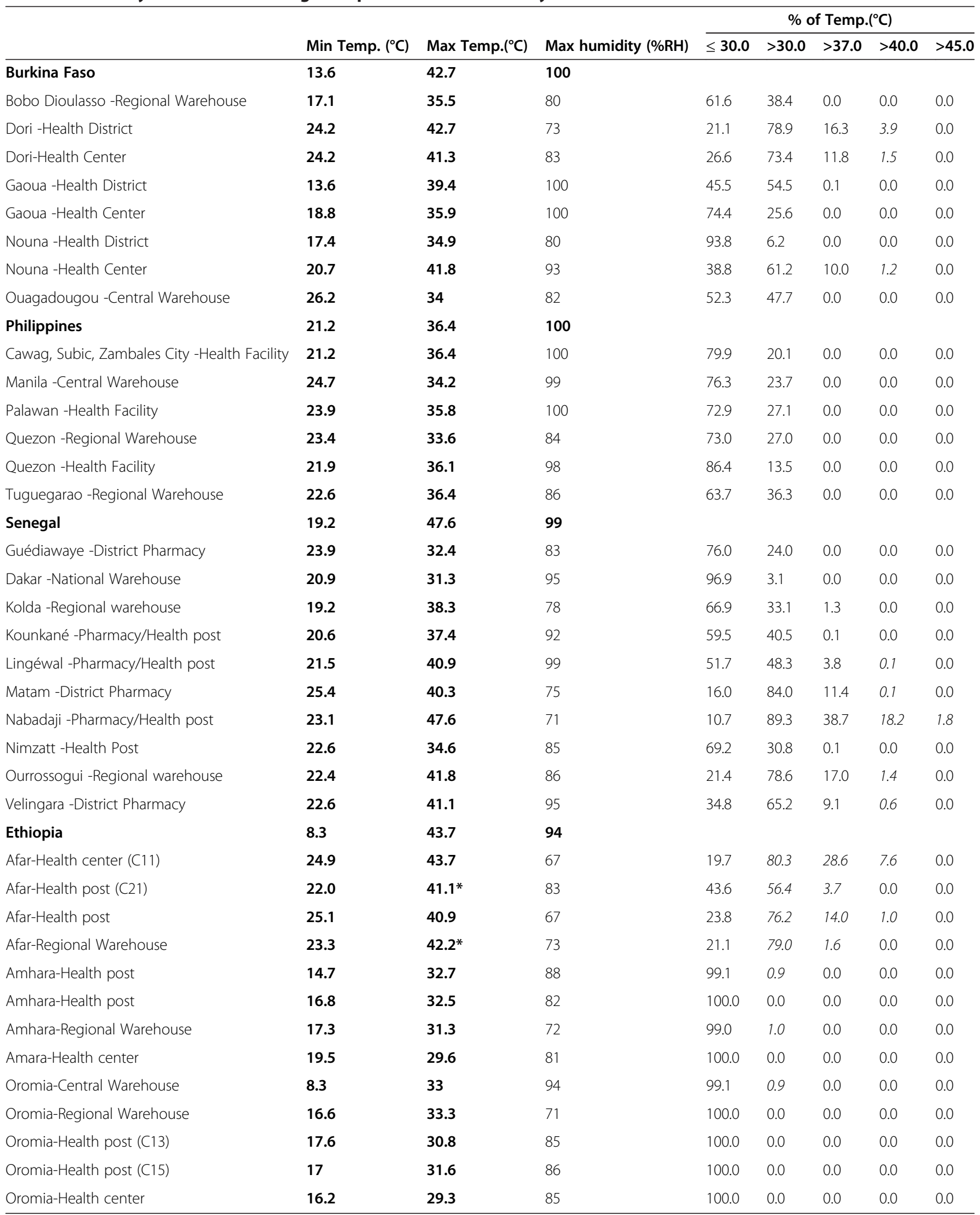

* Only one single temperature reading recorded above $40^{\circ} \mathrm{C}$.

The temperature ranges were based on manufacturer-recommended storage temperatures for the RDTs used in this study. Percentages of temperature recorded above the recommended limit for the RDTs uses in the country are highlighted in italics. 
and $4^{\circ} \mathrm{C}$ to $37^{\circ} \mathrm{C}$, respectively. One product targeted HRP2 antigen (single test line), and the other both aldolase and HRP2 antigens (two test lines).

\section{Results}

\section{Storage data}

Considerable variation was recorded in temperatures throughout the commodity supply chain, with temperatures ranging from $8.3^{\circ} \mathrm{C}$ to $47.6^{\circ} \mathrm{C}$ and a maximum humidity recorded of $100 \%( \pm 3 \mathrm{RH})$. Data are summarized in Table 1.

\section{Senegal}

Temperatures ranged from $19.2^{\circ} \mathrm{C}$ to $47.6^{\circ} \mathrm{C}$. In three facilities, at the regional, district level and health center level (in the regions of Matam, Nabadaji, and Ourossogui respectively), temperatures greater than $30.0^{\circ} \mathrm{C}$ were recorded for more than $70.0 \%$ of the time. At the central warehouse level in Dakar, temperatures below $30.0^{\circ} \mathrm{C}$ were recorded $96.9 \%$ of the time. Temperatures were also reported to be higher in the Kolda regional warehouse than in the pharmacy of Kounkané, and reached a maximum of $38.3^{\circ} \mathrm{C}$ and $37.4^{\circ} \mathrm{C}$ respectively.

Temperatures were particularly high at the Ourossogui regional warehouse (maximum $41.8^{\circ} \mathrm{C}$ ) and Nabadaji Pharmacy and Health Center (maximum $47.6^{\circ} \mathrm{C}$ ), where temperatures above $30.0^{\circ} \mathrm{C}$ were recorded every week (Figure 1). Each threshold line (red lines) indicated in figures 1 and 2 represents one of the manufacturerrecommended storage temperatures for the RDTs used in this study $\left(30,37,40,45^{\circ} \mathrm{C}\right)$.

\section{Burkina Faso}

Temperatures ranged from $13.6^{\circ} \mathrm{C}$ to $42.7^{\circ} \mathrm{C}$. In two facilities, the health district level and health centre level in the region of Dori, temperatures higher than $37.0^{\circ} \mathrm{C}$ were recorded for more than $11.8 \%$ of the total storage time. At the central warehouse level in Ouagadougou,

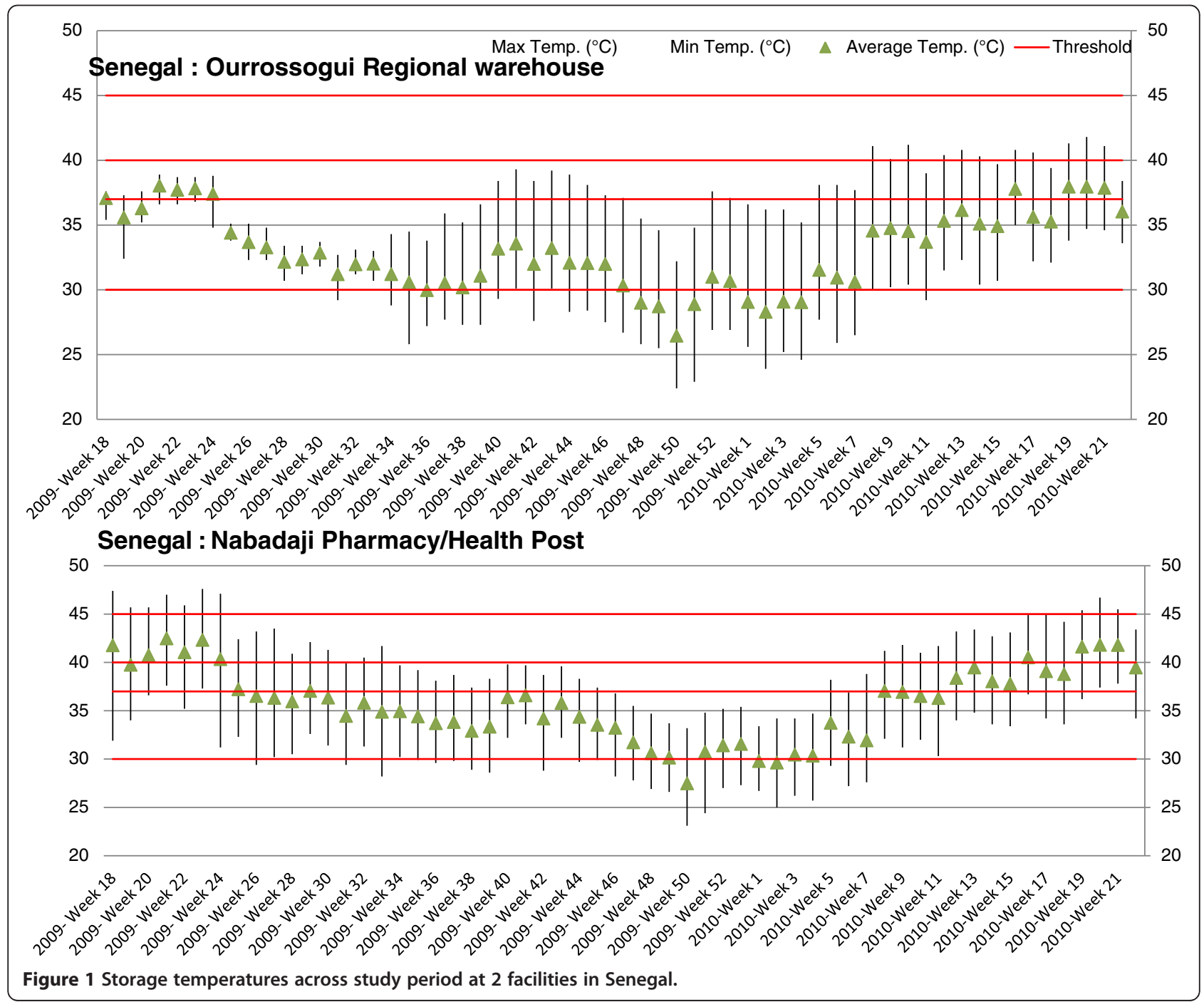


temperatures above $30.0^{\circ} \mathrm{C}$ were recorded $47.7 \%$ of the time. In Gaoua, temperatures were higher in the health district than in the more peripheral health centers, with maximums of $39.4^{\circ} \mathrm{C}$ and $35.9^{\circ} \mathrm{C}$ respectively.

\section{Ethiopia}

Temperatures ranged from $8.3^{\circ} \mathrm{C}$ to $43.7^{\circ} \mathrm{C}$. In two facilities, at health center and health post level in the region of Afar, temperatures over $40.0^{\circ} \mathrm{C}$ were recorded. At the central warehouse level in Addis, temperatures were over $30.0^{\circ} \mathrm{C}$ for $0.9 \%$ of the time. In Oromia and Afar regions, higher temperatures were reported at the central and regional warehouses than at the heath post level. Temperatures were particularly high in Afar region where temperatures above $37.0^{\circ} \mathrm{C}$ were recorded over several weeks between April and October in two health centers (Figure 2).

\section{The Philippines}

Temperatures ranged from $21.2^{\circ} \mathrm{C}$ to $36.4^{\circ} \mathrm{C}$. At the central warehouse level in Manila, temperatures higher than $30.0^{\circ} \mathrm{C}$ were recorded $23.7 \%$ of the time.

\section{Comparison with manufacturer-recommended temperatures}

In Burkina Faso, Senegal and Ethiopia storage temperatures exceeded the recommended RDT manufacturer temperature limits. In three out of eight facilities (one health district facility and two health centres) in Burkina Faso, temperatures rose above the recommended RDT manufacturer temperature limit of $40^{\circ} \mathrm{C}$. In 11 out of 13 facilities in Ethiopia (one health center, six health posts, two central warehouses, two regional warehouses), temperatures exceeded the recommended RDT manufacturer temperature limit of $30^{\circ} \mathrm{C}$, up to $80.3 \%$ of time at one site. In five out of ten facilities in Senegal (one regional warehouse, two district pharmacies, two pharmacies/health post), temperatures rose above the recommended RDT manufacturer temperature limit of $40^{\circ} \mathrm{C}, 18.2 \%$ of the time in one site (Table 1 ).

\section{Humidity}

All RDTs are sealed in foiled packages and should not been exposed to humidity before use, although humidity is a matter of concern only when an RDT package has

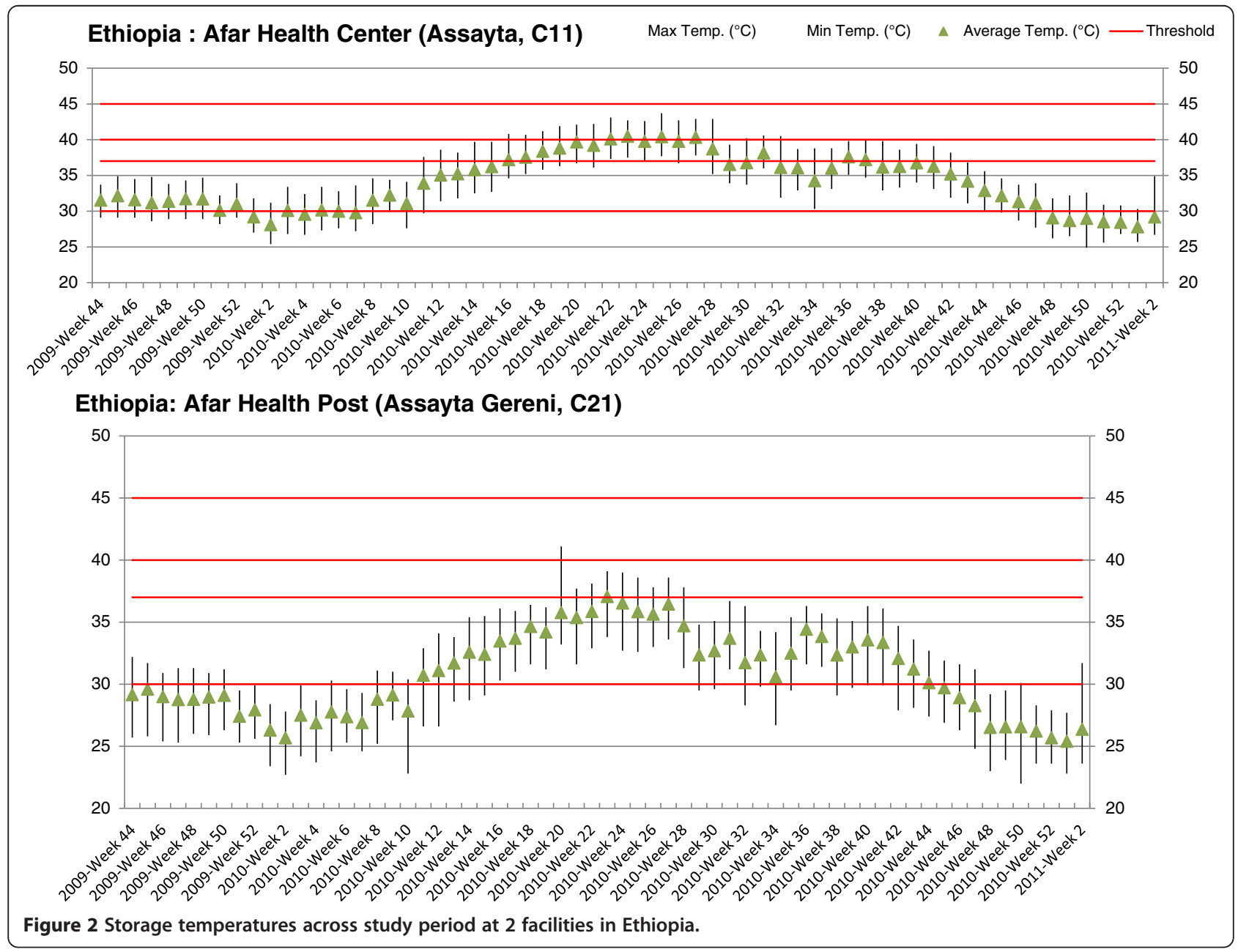


been damaged. Maximum humidity recorded ranges from 94 to $100 \%$ RH (Table 1).

\section{Transport data}

Thirty transport chains were recorded for the three countries (Senegal, Burkina Faso, and the Philippines).

From the national to the regional warehouse level, two different transport chains were recorded in Senegal and each transport took 25 hours (minimum $27.3^{\circ} \mathrm{C}$, maximum $38.8^{\circ} \mathrm{C}$ ). In Burkina Faso, nine different transport chains occurred and transport took between three to nine hours (minimum $24.4^{\circ} \mathrm{C}$, maximum $43^{\circ} \mathrm{C}$ ). In the Philippines, three transport episodes were recorded from the central and regional warehouses to health centers in Palawan, Mindoro and Tuguegarao. These involved both road and air conveyances. In all three cases, the average temperature remained within acceptable limits (minimum $22.1^{\circ} \mathrm{C}$, maximum $29.1^{\circ} \mathrm{C}$ ), with the exception of one transport chain segment where the maximum temperature rose to $41.5^{\circ} \mathrm{C}$. Data for all the transport chains are presented in Table 2 .

\section{Discussion}

The malaria rapid diagnostic tests monitored in this study were exposed to conditions above manufacturer recommendations in three of the four countries studied, though for only brief periods. However, in all countries, conditions within these supply lines were above $30^{\circ} \mathrm{C}$ for considerable periods- beyond the WHO recommendations for stability of pharmaceuticals that are delivered through similar supply chains [11], and thus for many other commercially-available malaria RDTs. While the countries appear to have selected RDTs with stated stability, in keeping with general transport and storage conditions in this limited survey, the results raise questions over adequacy of supply line management for other medical commodities. In the four countries, drugs and RDTs are stored under the same conditions; this illustrates the importance of understanding transport and storage conditions in RDT product selection [14].

Whether the periods of temperature exposure recorded here affect RDT quality depends on the stability of the individual products. Previous studies have shown a high variability in RDT stability, both for HRP2 detecting test lines and particularly for test lines detecting pLDH [1-4]. Stability can vary at times between lots of specific products $[1,3,15]$, but real-time stability data on a range of products lot-tested through the WHOFIND malaria RDT evaluation programme suggests that significant failures in tests stored within manufacturer recommendations are not common [16]. The products in use by public health services in the countries involved

Table 2 Transport chain conditions

\begin{tabular}{|c|c|c|c|}
\hline Transport chains (n) & Temperature range $\left({ }^{\circ} \mathrm{C}\right)$ & Transport duration (time) & Comments \\
\hline \multicolumn{4}{|l|}{ Senegal } \\
\hline \multirow[t]{2}{*}{ National-Regional warehouse (2) } & 27.3-38.8 & 25 hours & _No cool chain system \\
\hline & & & _Truck \\
\hline \multirow[t]{2}{*}{ Regional warehouse-Sanitary district (1) } & $31.6-34.4$ & 2 hours & _ No cool chain system \\
\hline & & & _Car \\
\hline \multirow[t]{2}{*}{ Sanitary district-Health post level (1) } & 31.0 (1 reading only) & 1 hour & _ No cool chain system \\
\hline & & & _Car \\
\hline \multirow[t]{2}{*}{ Health post level-health hut level (2) } & $31.1-42.9$ & 4-6 hours & _ No cool chain system \\
\hline & & & _Bicycle \\
\hline \multicolumn{4}{|l|}{ Burkina Faso } \\
\hline \multirow[t]{2}{*}{ Central-Regional warehouse (9) } & 24.4-43 & 3-9 hours & _No cool chain system \\
\hline & & & _Truck \\
\hline \multirow[t]{2}{*}{ Regional warehouse-health district level (7) } & 26.6-41.0 (no cool chain) & 3-9 hours & _No cool chain system (8) \\
\hline & $-3.6-32$ (cool chain) & & _Truck \\
\hline \multirow[t]{2}{*}{ Health district-health center (4) } & $26.6-41.7$ & 3-9 hours & _No cool chain system \\
\hline & & & _Van \\
\hline \multicolumn{4}{|l|}{ The Philippines } \\
\hline \multirow[t]{2}{*}{ Central-Regional warehouse-health center (3) } & $22.1-41.5$ & 10-17 days & _No cool chain system \\
\hline & & & _road and air conveyance \\
\hline \multirow[t]{2}{*}{ Regional warehouse-village Health center (1) } & 24.6-32 & 1 hour & _No cool chain system \\
\hline & & & _Van \\
\hline
\end{tabular}


in this study had maximum storage recommendations ranging from $40^{\circ} \mathrm{C}$ to $45^{\circ} \mathrm{C}$, well above the former $\mathrm{ICH}$ recommendations, but only exceeded these temperatures for relatively short periods of time. However, these temperatures are above the recommendations for many other malaria RDTs; only 13 of the 50 RDTs tested in the Round 3 of the WHO Product Testing Programme had recommended storage temperatures of $40^{\circ} \mathrm{C}$ or above (FIND, unpublished data).

Other commodities (with the exception of vaccines) are generally stored together in the same facilities at central, regional, and peripheral levels. For example, certain tablet formulations of anti-malarials (e.g., artemether-lumefantrine, artesunate, amodiaquine, sulphadoxine, pyrimethamine), and HIV antiretrovirals (e.g., lopinavir, ritonavir) listed as essential drugs should not be stored above $30^{\circ} \mathrm{C}$ [17].

These data raise a number of issues. Firstly, diagnostics (and drugs) clearly need to be selected taking into account the expected exposure to heat and humidity. While humidity is normally addressed by the moistureproof packaging in which the product is delivered, measuring temperature using electronic monitors is relatively easy and cheap. This knowledge should inform procurement criteria. As openly-available data on realtime stability is limited, it seems advisable for countries to require real-time heat stability data from manufacturers on which product storage recommendations should be based. It has been recommended to store RDTs at a central level for as long as possible on the assumption that peripheral storage is less controlled [18]. High temperatures recorded at central facilities in the four countries suggest that logistics planning should take actual storage data into account, and that managing conditions at central storage facilities should be taken more seriously. While storage standards for in-vitro diagnostic are less well defined, WHO standards for temperature stability of pharmaceuticals were exceeded at central storage over $23 \%$ of the time in two countries [11].

Clearly, published standards for pharmaceuticals and diagnostics in these climatic conditions are inadequate. Without substantial resources devoted to controlled transport and storage, temperatures of $30^{\circ} \mathrm{C}$ are routinely exceeded. There does appear to be a case here for investment in temperature control of central medical storage facilities. However, RDTs are a relatively high volume commodity, making controlled-temperature transport and storage at remote locations often impractical. Refrigeration is unnecessary for current products, and can also pose some risks, as shown in this study where one RDT was exposed to temperatures below $-3^{\circ} \mathrm{C}$ in Burkina Faso. RDT storage outside the manufacturer-recommended temperature could shorten RDT product shelf life, yet this is difficult to detect.
When RDTs are known to have been subjected to extreme conditions for some time, re-testing a batch withdrawn from the field against parasite panels is possible (e.g. lot testing laboratories in the Philippines and in Cambodia, [19], or comparing with microscopy, but both can be logistically difficult. Rejecting a batch on the basis of transport conditions without evidence of poor performance is costly. The development of positive control wells, based on lyophilized parasite antigens, holds promise to address clinic-level quality control dilemmas for malaria RDTs [20].

Lower cost solutions are available for remote-area storage, such as underground storage or the use of evaporative cooler boxes [21]. Storage using evaporative cooling has been demonstrated for malaria RDTs in Afghanistan [22] and Cambodia [23], reducing temperatures from as much as $37^{\circ} \mathrm{C}$ to $23^{\circ} \mathrm{C}$ without use of electricity, well within the common range for storage of non-vaccine medical commodities. Moreover, simple measures during transport, such as loading and discharging vehicles in the shade or at night, reduce the probability of deterioration $[21,24]$. In the end, the performance of the product at end-user level is the most important measure of impact of previous environmental damage; this is difficult to sustain for both diagnostics and drugs. Whereas this is currently being addressed for malaria, monitoring the availability of the active ingredient of a drug in a remote location is likely to remain a major challenge.

Due to the complexities of coordinating logistics throughout transport chains, only segments of the transport chain were recorded in this study. A larger study would likely reveal a wider range of conditions and problems. Since only a small sample of transport and storage was collected in each country, the results cannot be considered fully representative of the conditions under which medical commodities are transported and stored in any of these countries. However, they illustrate the lack of control in supply chains and potential for environmental damage of products. Ideally, the condition of RDTs should also have been tested; the countries concerned procure RDTs with relatively high recommended maximum storage temperatures so it is unclear whether the relatively short periods when they are exposed to higher temperatures would have been significant. However, the study results raise concern with respect to RDT stability between production lots (pre-release real-time testing of production lots is obviously not possible $[1,3]$, as well as the effect of their co-storage with other perishable medical commodities, as discussed above.

\section{Conclusion}

Transport and storage temperatures varied widely throughout the supply chains monitored here. In particular high temperatures were recorded at central 
storage facilities in some countries. While the recommended storage conditions of the RDTs used by these health services were rarely exceeded, conditions were inappropriate for many of the RDTs on the market and frequently exceeded common pharmaceutical storage standards. A number of simple measures can be instituted to lower ambient temperatures, and tests for commodity quality control are clearly needed. The results illustrate the importance of health services understanding their supply chain conditions and matching product procurement to these. They also suggest that a revisit of standards is indicated for medical commodities in general in the tropics and sub-tropics, as existing standards for Climatic Zones III and IV appear inadequate on the basis of this study.

\section{Competing interests}

The authors declare they have no competing interests.

\section{Authors' contributions}

$\mathrm{AA}, \mathrm{DB}$ and $\mathrm{EL}$ designed the study protocol and instructions. MM, KO, ID, OG, $A G$ and SM carried out the monitoring and data collection process. AA and EL carried out the analysis. AA, SOC, BF, MS, JB, DB and EL drafted the manuscript. All authors have read and approved the manuscript.

\section{Acknowledgements}

We would like to thank the ministries of health, the health facility staff in Ethiopia, Burkina Faso, Senegal and the Philippines for their support in collecting data for this study. The study was funded by the Foundation for Innovative New Diagnostics (FIND), through grants from the Bill and Melinda Gates Foundation and the UK Department for International Development (DFID)

\section{Author details}

${ }^{1}$ Foundation for Innovative New Diagnostics (FIND), Geneva, Switzerland. ${ }^{2}$ Université de Ouagadougou, Ouagadougou, Burkina Faso. ${ }^{3}$ Ethiopian Health and Nutrition Research Institute, Addis Ababa, Ethiopia. ${ }^{4}$ Université Cheikh Anta Diop, Dakar, Senegal. ${ }^{5}$ Research Institute of Tropical Medicine, Manila, Philippines. ${ }^{6}$ National Malaria Control Programme of Senegal, Dakar, Senegal.

Received: 12 September 2012 Accepted: 29 November 2012 Published: 6 December 2012

\section{References}

1. WHO: Malaria rapid diagnostic test performance: results of WHO product testing of malaria RDTs: round 3 (2010-2011). Geneva: World Health Organization; 2011.

2. WHO: Malaria rapid diagnostic test performance: results of WHO product testing of malaria RDTs: round 2 (2009). Geneva: World Health Organization; 2010.

3. WHO: Malaria rapid diagnostic test performance: results of WHO product testing of malaria RDTs: round 1 (2008). Geneva: World Health Organization; 2009.

4. Chiodini PL, Bowers K, Jorgensen P, Barnwell JW, Grady KK, Luchavez J, Moody AH, Cenizal A, Bell D: The heat stability of Plasmodium lactate dehydrogenase-based and histidine-rich protein 2-based malaria rapid diagnostic tests. Trans R Soc Trop Med Hyg 2007, 101:331-337.

5. WHO: Guidelines for the treatment of malaria. 2nd edition. Geneva: World Health Organization; 2010.

6. WHO: World Malaria Report, 2011.: World Health Organization; 2011. http:// www.who.int/malaria/world_malaria_report_2011/9789241564403_eng.pdf.

7. Jorgensen P, Chanthap L, Rebueno A, Tsuyuoka R, Bell D: Malaria rapid diagnostic tests in tropical climates: the need for a cool chain. Am J Trop Med Hyg 2006, 74:750-754.

8. ICH: ICH harmonized tripartite guideline: Stability testing of new drug substances and products Q1A(R2): Current Step 4 version; 2003. Date accessed: 2012, http://www.ich.org/fileadmin/Public_Web_Site/ICH_Products/ Guidelines/Quality/Q1A_R2/Step4/Q1A_R2__Guideline.pdf.
9. ICH: Q1F Stability Data Package for Registration Applications in Climatic Zones III and IV: Q1F Explanatory Note; 2006. Date accessed: August 2012, http:// www.ich.org/fileadmin/Public_Web_Site/ICH_Products/Guidelines/Quality/ Q1F/Q1F_Explanatory_Note.pdf.

10. ASEAN: ASEAN Guideline on Stability Study of Drug Product; 9th ACCSQPPWG Meeting, Philippines, 21-24 Feb 2005. In ASEAN Guideline on Stability Study of Drug Product; 9th ACCSQ-PPWG Meeting, Philippines; 2005. Date accessed: December 2012, http://www.hsa.gov.sg/publish/etc/medialib/ hsa_library/health_products_regulation/western_medicines/files_guidelines. Par.61592.File.dat/ACTR_GuidelineforDrugProductStabilityStudy_Apr05.pdf.

11. WHO: Annex 2 to WHO Technical Report Series, No. 953: Stability testing of active pharmaceutical ingredients and finished pharmaceutical products; 2010.

12. NMSA: Climatic and agro climatic resources of Ethiopia. NMSA Meteorological Research Report Series, vol. 1, No. 1. Addis Ababa: Ethiopia; 1996.

13. Philippine Atmospheric, Geophysical and Astronomical Services Administration (PAGASA): National meteorology, climate data section. In Book Philippine Atmospheric, Geophysical and Astronomical Services Administration (PAGASA). National Meteorology, Climate Data Section; 2004.

14. WHO: Good practices for selecting and procuring rapid diagnostic tests for malaria. pp. 1-110. Geneva: WHO; 2011:1-110.

15. WHO/FIND/CDC: Methods manual for product testing of malaria rapid diagnostic tests (version 1). Manila: World Health Organization - Regional Office for the Western Pacific; 2008.

16. Results for malaria RDT lot testing; http://www.finddiagnostics.org/programs/ malaria-afs/malaria/rdt_quality_control/lot_testing/ malaria_rdt_lot_testing_results/.

17. Essential drugs practical guidelines; http://www.refbooks.msf.org/MSF_Docs/ En/Essential_drugs/ED_en.pdf.

18. WHOMPRO: Transport and Storage of Malaria RDTs; 2012. Date accessed: August 2012, http://www2.wpro.who.int/sites/rdt/using_rdts/rdt_transport_storage.htm.

19. Lot testing of malaria rapid diagnostic tests (RDTs); http://www.finddiagnostics. org/programs/malaria-afs/malaria/rdt_quality_control/lot_testing/.

20. Lon CT, Alcantara S, Luchavez J, Tsuyuoka R, Bell D: Positive control wells: a potential answer to remote-area quality assurance of malaria rapid diagnostic tests. Trans R Soc Trop Med Hyg 2005, 99:493-498.

21. World Health Organization-Western Pacific Regional Office (WHO-WPRO) UDP, Foundation for Innovative New Diagnostics (FIND), Roll Back Malaria Partnership, President's Malaria Initiative (PMI), UNICEF: Transporting, Storing, and Handling Malaria Rapid Diagnostic Tests at Central and Peripheral Storage Facilities. Arlington, Va: USAID | DELIVER PROJECT, Task Order 3; and Manila: WHO-WPRO; 2009

22. Mikhail AF, Leslie TJ, Mayan MI, Zekria R, Mohammad N, Hasanzai MA, Safi N, Whitty CJ, Rowland M: Field trial of three different Plasmodium vivax-detecting rapid diagnostic tests with and without evaporative cool box storage in Afghanistan. Malar J 2011, 10:169.

23. Chanthap L, Ariey F, Socheat D, Tsuyuoka R, Bell D: Low-technology cooling box for storage of malaria RDTs and other medical supplies in remote areas. Malar J 2010, 9:31.

24. World Health Organization-Western Pacific Regional Office (WHO-WPRO) UDP, Foundation for Innovative New Diagnostics (FIND), Roll Back Malaria Partnership, President's Malaria Initiative (PMI), UNICEF: Transporting, Storing, and Handling Malaria Rapid Diagnostic Tests in Health Clinics. Arlington, Va: USAID | DELIVER PROJECT, Task Order 3; and Manila: WHO-WPRO; 2009.

\section{doi:10.1186/1475-2875-11-406}

Cite this article as: Albertini et al: Malaria rapid diagnostic test transport and storage conditions in Burkina Faso, Senegal, Ethiopia and the Philippines. Malaria Journal 2012 11:406. 